be cross-questioned about the authenticity of his facts : it is exasperating when the reader has to guess whether this is the explanation, or only whether it might well be the explanation. A symptom of this failing is the paucity of references (though there are many more than there were in the second edition) and the absence of an author index.

The book has been enlarged by some seventy-five pages, mostly by the interpolation of new paragraphs. Its scope remains as it was: chapters on growth and cell division, differentiation (with a considerable amount of new material), plant movements, and the effects of external stimuli on movement and development. Bünning's own views on photoperiodism and endogenous rhythms are well summarized, together with recent experiments which appear to corroborate his hypothesis.

In a book which covers such a wide sweep of knowledge any critic can find omissions; a few of them are mentioned here only in the hope that they may be repaired in a fourth edition. The discussion of the relation between respiration and growth (pp. 84-91) is not convincing, and needs fuller and more critical treatment. The section on weed killers (p. 132) might well be expanded, for it omits so much that it is not easy to understand the residue. The section on stomatal movement (p. 429) is not up to date. Vernalization ( $p .473$ ) receives a scant three and a half pages, which seem inadequate in a book which specializes in developmental physiology. Finally, one is bound to say that the style suffers from a Teutonic turgidity, and the index is not nearly full enough for an important work of reference of this kind.

However, these are criticisms of detail, and they do not detract seriously from the massive erudition of the book and the fecundity of its ideas. It cannot be denied that the most powerful weapons in plant physiology are the techniques of physies and chemistry, and that sooner or later every physiological problem needs these weapons for its solution. But as more mature physiological problems reach the stage which requires the ehemist's technique, new problems emerge from the experience of naturalists and gardeners and agriculturists; and these can be tackled by the techniques of biology. Anyone who doubts such an assertion as this has only to read Bünning's book. For the English student, who is likely to hear all too little of this fascinating field of physiology, the book has a great deal to offer, and it is to be hoped that sooner or later an English translation will be available.

E. AsHBY

\section{THE RARER METAL, ZIRCONIUM}

\section{Zirconium}

By Dr. G. L. Miller, (Metallurgy of the Rarer Metals No. 2.) Pp. xviii +382. (London: Butterworths Scientific Publications; New York: Academic Press, Inc., 1954.) 45s. net.

T HIS book is the outcome of its author's desire to collate the information on zirconium which has been accumulating so rapidly during the past few years. Dr. G. L. Miller has been in an advantageous position to do this by reason of his own wide experience and also because of his visits to workers in the same field in the United States. As a result of his work, he has written this text-book and reference volume which will appeal to every chemist and metallurgist interested in zirconium. There are eighteen chapters, the first of which opens with the history and the occurrence of zirconium, its consump. tion and uses both as metal and alloys and, naturally, as a refractory material. The treatment in all cases is as thorough as the available data will permit, and the very carefully assembled bibliography at the end of each chapter is up to date and of notable dimensions. Methods of extracting the metal and the preparation of pure zirconium compounds are discussed in some detail, in particular the separation of hafnium and zirconium from one another. Earlier and more recent production methods are described, notably the van Arkel or iodide process and the Kroll processes in which purification and reduction are combined. Reduction of the tetra-chlorides of titanium and zirconium and the arc-dissociation of halides, and also methods of electrodeposition from fused salts as well as from aqueous and non-aqueous solutions, receive attention.

Following a general account of the structure, crystallographic, atomic and nuclear characteristics, attention is given to physical properties. Thermal, electrical, optical, thermionic and magnetic properties are reviewed and illustrated by graphs. There are two chapters on the mechanical properties of zirconium metal, and on zirconium alloys at room and at elevated temperatures. In this latter chapter, alloys of some twenty-four elements are included, not counting the zirconium alloys with oxygen and nitrogen which receive separate treatment in the following chapter. The chemical and corrosion resisting properties of the metal and its alloys and their resistance to the action of liquids in general and to some of the concentrated mineral acids as well as a range of organic acids is illustrated by a series of useful tables. Probably the most valuable and generally useful chapter in the book is that on alloys of zirconium, in which first the alloying theory and its application to zirconium is discussed on a theoretical basis and then the practical results of comparatively recent investigations of binary systems involving zirconium are reported with phase diagrams of many of the binary alloys. This chapter has a bibliography involving more than eighty references and covering all the contemporary useful contributions to the subject. The chapter on melting practices discusses those types of furnace that can be applied to zirconium and is followed by an account of fabricating the metal by rolling, extrusion and other techniques, in which brazing and soldering are not lost sight of and attention is directed to the fact that zirconium has superior wetting and very good bonding qualities.

The powder metallurgy of zirconium has its own chapter in which the conclusions of H. A. Hausner and his colleagues at Sylvania Electric Products, Inc., Bayside, Long Island, New York, that zirconium is readily fabricated by powder methods are confirmed. The most important part of the chapter deals with the preparation of zirconium powder. The last chapter covers special compounds such as the nitride, the carbide, the boride and the silicide, but there is a valuable appendix dealing with some eleven methods of preparing material for metallographic examinations.

The usefulness of the chapter bibliographies is increased by the addition of a final black numeral or numerals to each reference denoting the page upon which the reference is cited, a distinct advantage to the busy worker who quickly wants to find where the reference appears and its specific terms.

H. W. Greenwood 